\title{
CONTRIBUIÇÃO PARA AVALIAÇÃO DO DESEMPENHO DE REVESTIMENTOS CONTRAFOGO EM ELEMENTOS DE CONCRETO ARMADO SUBMETIDOS A TEMPERATURAS ELEVADAS
}

\author{
C. BRITEZ ${ }^{1}$, V. P. SILVA ${ }^{2}$, P. HELENE ${ }^{3}$ \\ ${ }^{1}$ Pesquisador de Pós-Doutorado na Escola Politécnica da USP, Britez Consultoria, São Paulo, Brasil \\ ${ }^{2}$ Professor da Escola Politécnica da USP, São Paulo, Brasil \\ ${ }^{3}$ Professor Titular da Escola Politécnica da USP, PhD Engenharia, São Paulo, Brasil
}

\section{RESUMEN}

Atualmente, é complexo subsidiar tecnicamente o uso de revestimentos contrafogo, em pelos menos duas situações: em obras de retrofit, em que o cobrimento de concreto da edificação existente não possui espessura em conformidade com as prescrições das normas vigentes brasileiras ABNT NBR 6118:2014 e ABNT NBR 15200:2012 para um dado TRRF (Tempo Requerido de Resistência ao Fogo); bem como justificar a compensação da espessura de cobrimento (visando a ação do fogo) em elementos de concreto com falhas construtivas ou erros de projeto (relacionados com espessura insuficiente) em obras "novas" (construídas, em teoria, com as normas vigentes). A ABNT NBR 15200:2012 não apresenta alternativas claras para os casos excepcionais do não cumprimento da norma, devido a um cobrimento com espessura inferior aos tabulados, a não ser, evidentemente, pela redução automática do TRRF, o que, na prática, já pode resultar numa situação de não conformidade pela ABNT NBR 14432:2001 e Instruções Técnicas nacionais do Corpo de Bombeiros. Nesse contexto, este artigo visa comparar diferentes sistemas de revestimento contrafogo ${ }^{1}$ (em relação a uma amostra de referência, sem revestimento), aderidos a elementos de concreto armado, com um ano de idade e cobrimento de $1,5 \mathrm{~cm}$, (para simular a situação das obras de retrofit, ou de elementos com falhas construtivas e erros de projeto relacionados à espessura insuficiente de cobrimento) e, avaliar o desempenho desses sistemas de revestimento por meio de inspeção visual e verificação da evolução das temperaturas internas após ensaios experimentais de simulação de incêndio, com uso de termopares previamente instalados, em um forno de grande porte com sistema de queimadores a gás natural, por um tempo de 120 minutos, sob a curva ISO 834. Os resultados demonstraram que é possível obter correlações bem próximas às da literatura consagrada quando envolvido revestimentos em argamassa base cimento, bem como outras particularidades fundamentais sobre revestimentos em gesso e ainda a possibilidade do uso de tintas intumescentes como proteção passiva em elementos de concreto armado.

Palabras clave: incêndio; revestimento contrafogo; concreto; proteção passiva; programa experimental.

\footnotetext{
${ }^{1}$ A premissa da pesquisa é a de usar os próprios revestimentos naturais de uma edificação (argamassa e gesso), bem como a opção de tinta intumescente, para um elemento de concreto armado construído propositadamente com cobrimento de $1,5 \mathrm{~cm}$ (aquém das especificações de um TRRF de 120 minutos).
} 


\section{ABSTRACT}

Currently, it is complex to technically support the use of fire coatings in at least two situations: in retrofitting works, in which the concrete covering of the existing building does not have a thickness in accordance with the requirements of the current Brazilian standards (ABNT NBR 6118: 2014 and ABNT NBR 15200: 2012) for a given TRRF (Required Fire Resistance Time); as well as to justify the compensation of the thickness of the cover (with the aim of fire action) in concrete elements with constructive faults or design errors (related to insufficient thickness) in "new" works (constructed, in theory, with current regulations). ABNT NBR 15200: 2012 does not provide clear alternatives for exceptional cases of non-compliance with the standard, due to a coating with a thickness less than the tabulated, except, of course, for the automatic reduction of the TRRF, which, in practice, can already result in a situation of non-compliance by ABNT NBR 14432: 2001 and Technical Instructions of the Fire Department. In this context, this article aims at comparing different fireproof coating systems (in relation to a reference sample, uncoated), adhered to reinforced concrete elements, one year old and covered by $1.5 \mathrm{~cm}$ (to simulate the situation of retrofit works, or elements with constructive faults and design errors related to insufficient thickness of cover), and evaluate the performance of these coating systems by means of visual inspection and verification of the evolution of the internal temperatures after experimental tests of fire simulation, with the use of thermocouples previously installed, in a large furnace with a natural gas burner system, for a time of 120 minutes, under the ISO 834 curve. The results showed that it is possible to obtain correlations very close to those of the classical literature when involved cement-based mortar, as well as other fundamental aspects of the gipsum coat and also the possibility of the use of intumescent paints as passive protection in elements of reinforced concrete. The results showed that it is possible to obtain correlations very close to those of the classical literature when involved cement-based mortar, as well as other fundamental aspects of the gypsum coating and also the possibility of the use of intumescent paints as passive protection in elements of reinforced concrete.

Key words: fire; concrete; fire protection coating; passive fire protection.

\section{INTRODUÇÃO E REVISÃO DA LITERATURA}

Por possuir um comportamento em situação de incêndio bem parecido ao do concreto, o uso de revestimentos de argamassa base cimento como proteção passiva, já está bem consolidado no meio técnico. Não obstante, apesar da normalização vigente (ABNT NBR 15200:2012) condicionar a utilização dos revestimentos de gesso, vermiculita e fibras à realização de ensaio experimental que comprove a sua eficiência, há históricos de recomendação e utilização desses materiais desde a década de 80 LANDI (1986) e ALMEIDA (1984). Malhotra (1982) aponta que a gipsita é calcinada a cerca de $150{ }^{\circ} \mathrm{C}$ para produzir gesso $\left(\mathrm{CaSO}_{4} \cdot 1 / 2 \mathrm{H}_{2} \mathrm{O}\right)$, que quando misturado com a água reverte mais uma vez em gipsita. Pode ser usada misturada com areia, cal ou com agregados leves como perlita ou vermiculita. Em exposição a elevadas temperaturas, muda para o hemidrato entre $100{ }^{\circ} \mathrm{C}$ e $140{ }^{\circ} \mathrm{C} \mathrm{e}$ libera uma quantidade significativa de umidade que, por sua vez, absorve uma quantidade significativa de calor. Entre $400{ }^{\circ} \mathrm{C}$ e $500^{\circ} \mathrm{C}$, o hemidrato se calcina e se transforma em anidro insolúvel.

Complementando, Alexander (1982) acena que a resistência ao fogo do gesso pode ser atribuída a uma série de razões. Os cristais de gesso contêm $50 \%$ de água em volume e cerca de $21 \%$ em massa. A elevadas temperaturas, as estruturas revestidas por gesso permanecem íntegras a cerca de $100{ }^{\circ} \mathrm{C}$ a 140 ${ }^{\circ} \mathrm{C}$ até o gesso ser transformado em hemidrato; e a temperatura não excede os $250{ }^{\circ} \mathrm{C}$ até que se conclua a desidratação formando o sulfato de cálcio anidro. Esse comportamento possui vantagens como, por exemplo, eliminar o choque térmico, impedindo o desplacamento prematuro do concreto ou a sua 
expansão térmica excessiva. Limita ainda a expansão da estrutura revestida restringindo o seu aumento de temperatura e, dessa forma, aumentando o tempo de resistência ao fogo.

Sobre as tintas intumescentes, são numerosas as pesquisas em estruturas de aço, onde esse sistema de revestimento é bastante utilizado como revestimento contrafogo (SILVA; BILOTTA; NIGRO, 2017; ATEFI; NADJAI; ALI, 2017; OGRIN; SAJE; HOZJAN, 2017; LUCHERINI; MALUK, 2017), mas não se tem muito registro, em artigos científicos, sobre a aplicação em estruturas de concreto. Nesse contexto, no programa experimental abordado neste artigo, o produto empregado se trata de uma tinta acrílica à base de água, de aparência semelhante às pinturas convencionais. Quando em contato com temperaturas superiores a $200{ }^{\circ} \mathrm{C}$, inicia-se a intumescência, resultando na expansão da camada de proteção em até 60 vezes a espessura seca original do material, promovendo a proteção térmica do substrato de concreto.em temperaturas superiores a $1000^{\circ} \mathrm{C}$.

\section{PROGRAMA EXPERIMENTAL}

Foram realizados dois eventos de ensaio com quatro elementos de concreto cada, com idades de um ano e $f_{c k}$ de $25 \mathrm{MPa}$, sob a curva-padrão de incêndio ISO 834 pelo tempo de 120 minutos (2 h), no Laboratório de Segurança ao Fogo e a Explosões (LSFEx) do IPT (Instituto de Pesquisas Tecnológicas), situado na Cidade Universitária, na Rua Almeida Prado, 532, Butantã, São Paulo. A avaliação foi realizada durante e após o ensaio, por intermédio de inspeção visual (análise do grau/intensidade de spalling) e com referência a um elemento não revestido (em cada evento de ensaio). Cada elemento possuía 2,40 $\mathrm{m}$ de altura, $30 \mathrm{~cm}$ de profundidade e $40 \mathrm{~cm}$ de largura.

Além disso, foi analisada (principalmente) a capacidade protetiva do revestimento e de seu isolamento por meio da evolução de temperaturas no interior do elemento de concreto, que foi monitorada por meio de sete termopares por elemento (total de 28 termopares por ensaio), instalados estrategicamente na massa de concreto (por elemento, foram seis no interior da massa de concreto e um na sua parte externa, para aferição da capacidade de isolamento de temperatura), conforme exposto nas Fig. 1 e 2.

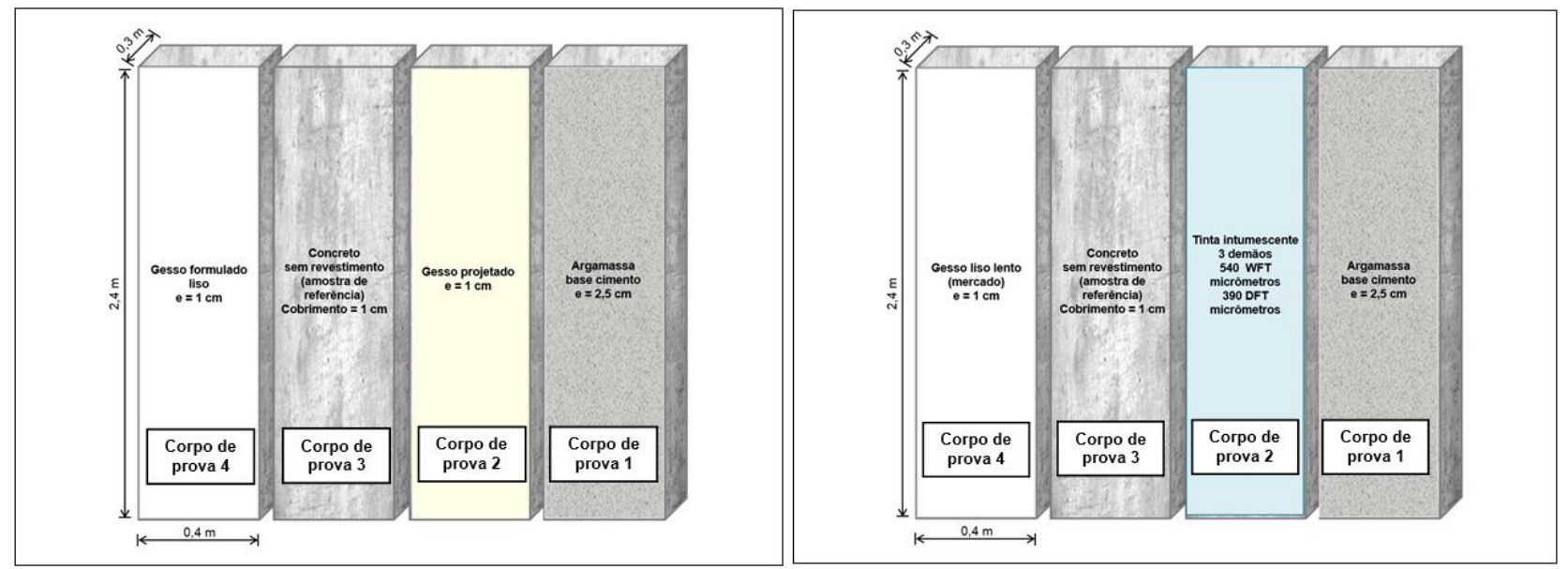

Figura 1. Elementos e respectivos revestimentos ensaiados nos dois eventos de simulação de incêndio (evento 1 à esquerda e evento 2 à direita). 


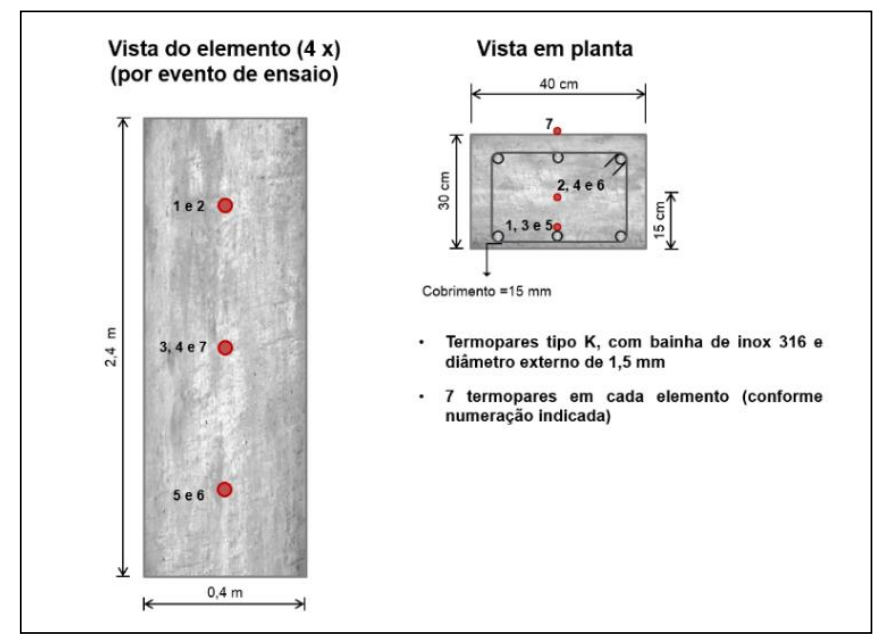

Figura 2. Detalhe da locação dos termopares para ambos os ensaios.

Ao todo, foram ensaiados cinco tipos de revestimentos contrafogo: gesso liso lento popular de mercado e gesso formulado liso (aplicados manualmente), argamassa base cimento industrializada comum (preparada in loco), tinta intumescente e gesso projetado (aplicado com auxílio de equipamento industrial de projeção). O gesso liso lento de mercado, o gesso formulado e o gesso projetado possuem composições químicas distintas, conforme será discutido adiante, em função de sua procedência.

\section{1 Detalhes da construção dos elementos e aplicação dos sistemas de revestimento}

Em setembro de 2017 houve a montagem das fôrmas e armaduras (estribos armados com ganchos conforme Kodur, 2005), instalação dos termopares, além da construção dos elementos de concreto propriamente ditos no interior do galpão cedido pelo IPT, em São Paulo. Foi empregado um concreto com uso de cimento tipo CP II-E-40, areia fina natural quartzosa de cava, areia de brita e britas do tipo calcário. A água foi fixada em $175 \mathrm{~L} / \mathrm{m}^{3}$ e foi utilizado um aditivo do tipo mid-range para uma consistência de $20 \pm 3 \mathrm{~cm}$, aferida por meio de slump-test. Conforme planejado, somente um caminhão betoneira foi envolvido na concretagem dos oito elementos, não dando margem para variação do material concreto quando das análises dos resultados dos ensaios experimentais de simulação de incêndio. As oito amostras, portanto, foram construídas nas mesmas condições e com os mesmos lotes de materiais (fôrma, concreto, armadura e termopares). O evento de concretagem foi controlado e corpos de prova foram rompidos no laboratório da da empresa de serviços de concretagem, onde se apurou as resistências à compressão de 20,2 $\mathrm{MPa}(7$ dias) e 25,6 MPa (28 dias), respectivamente. Os valores obtidos foram compatíveis com o $f_{c k}$ de $25 \mathrm{MPa}$ previsto para idade de 28 dias.

Após a construção dos oito elementos, aguardou-se um prazo de maturidade do concreto (grau de hidratação) equivalente ao que normalmente ocorre em obra, de seis meses, para aplicação dos sistemas de revestimentos contrafogo (preparo de base e camada de revestimento propriamente dita) nos elementos construídos. Durante esses seis meses os elementos foram armazenados dentro do galpão e ainda protegidos com uma lona plástica não aderida, somente para evitar impregnação de sujidades na superfície ou outros tipos de avaria ou até vandalismo. Em março de 2018, conforme previsto, todos os revestimentos contrafogo foram aplicados.

Nos quatro elementos referentes ao primeiro evento de ensaio foram aplicados três tipos de revestimento (em um deles, o de referência, não foi aplicado nenhum revestimento): gesso formulado liso tipo M30, de aplicação manual com desempenadeira lisa de aço; gesso projetado tipo P80, de aplicação com uso da máquina de projeção tipo M280; e argamassa industrializada tipo Multimassa Uso Geral, comercializada em sacos de $20 \mathrm{~kg}$. 
Nos quatro elementos referentes ao segundo evento de ensaio também foram aplicados três tipos de revestimento (assim como no primeiro evento, em um dos elementos, o de referência, não foi aplicado revestimento): gesso liso lento popular de mercado, de aplicação manual com desempenadeira lisa de aço; tinta intumescente, tipo CKC-333; e argamassa industrializada tipo Multimassa Uso Geral, comercializada em sacos de $20 \mathrm{~kg}$.

Tanto o gesso liso quanto o gesso projetado foram aplicados com espessura de $1,0 \mathrm{~cm}$, controlada com uso de gabarito e paquímetro digital. A tinta intumescente foi aplicada em três demãos totalizando uma espessura úmida de 540 micrometros, termo internacionalmente conhecido como WFT (Wet Film Tchikness), o que corresponde a 390 micrometros seca, termo conhecido como DFT (Dry Film Tchikness). As camadas de revestimento propriamente ditas foram aplicadas aproximadamente 15 dias após o preparo da base com chapisco [rolado (próprio para gesso) e desempenado (próprio para argamassa)], seguindo os prazos que comumente ocorrem em obra. De março de 2018 ao final de agosto de 2018, os elementos foram mantidos descobertos dentro do galpão do IPT, com o intuito de promover a maturidade e grau de hidratação suficientes dos revestimentos, como numa situação normal de obra, conforme Fig. 3.

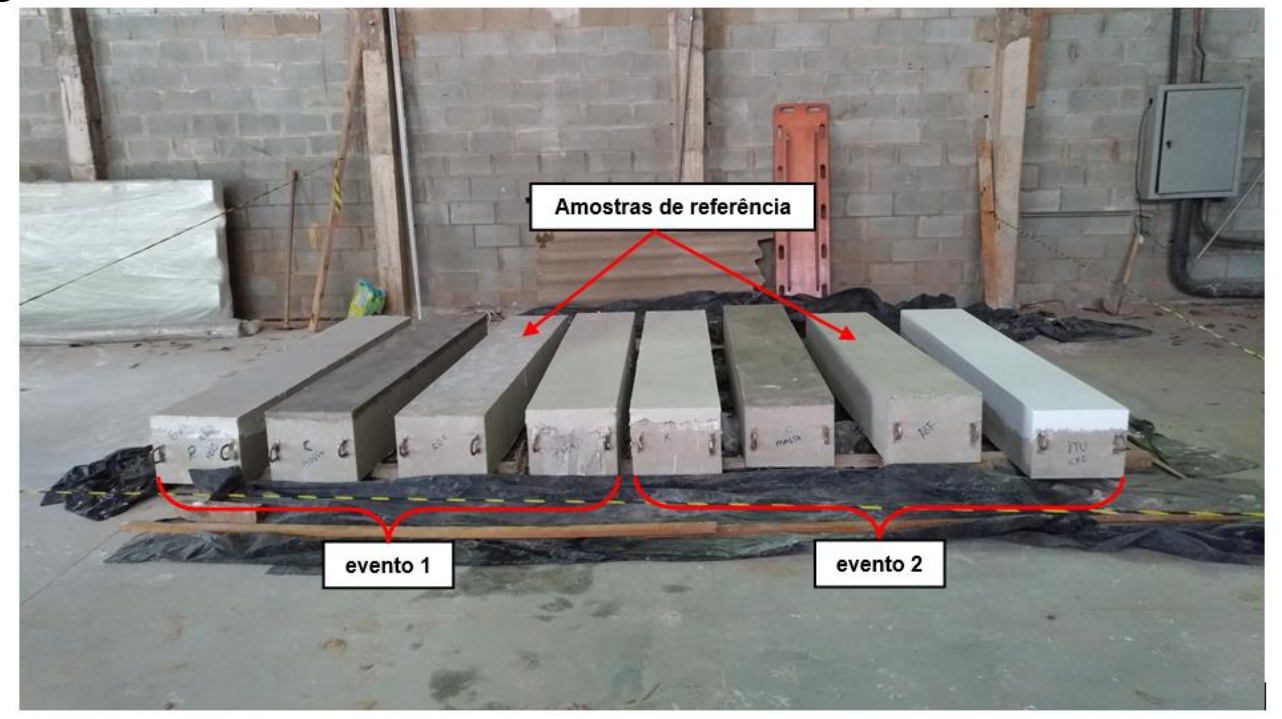

Figura 3 - Detalhe dos elementos finalizados com todos revestimentos aplicados, exceto nas duas amostras de referência.

\subsection{Detalhes dos ensaios de simulação de incêndio}

Os ensaios propriamente ditos de simulação de incêndio foram realizados no forno do Laboratório de Segurança ao Fogo e Explosões do Instituto de Pesquisas Tecnológicas de São Paulo (IPT-SP), centro de excelência em tecnologia do Brasil e de referência nesse tipo de ensaio, cujas dimensões são compatíveis com o programa térmico planejado. O forno utilizado no programa experimental possui um sistema com cinco queimadores a gás natural, dispostos nas duas paredes laterais e posicionados de modo que não haja encontro frontal entre eles.

\subsection{Primeiro evento de ensaio (evento 1)}

Os quatro elementos do primeiro evento de ensaio foram ensaiados de uma só vez, sem carregamento e basicamente com a exposição de uma face ao fogo (maior face com largura de $40 \mathrm{~cm}$ e altura de 2,40 $\mathrm{m}$ ), a fim de avaliar bem a influência do revestimento sem qualquer interferência, o que propiciou ainda que a face posterior (onde os termopares estavam instalados) permanecesse de livre acesso durante o ensaio de simulação de incêndio. Precedentemente ao ensaio, após 11 meses da construção dos elementos, novamente corpos de prova de controle foram rompidos apurando-se a resistência à 
compressão de 30,4 MPa. Na data de 30 de agosto de 2018 ocorreu o primeiro evento de simulação de incêndio, sob a curva ISO 834, por um tempo de 120 minutos.

A máxima temperatura atingida no elemento de concreto de referência, a $1,5 \mathrm{~cm}$ de profundidade, sem revestimento (corpo de prova 3), aos 120 minutos de ensaio, foi de $553{ }^{\circ} \mathrm{C}$, correspondente ao termopar de número 1 localizado na armadura próxima a face exposta ao fogo. Já as máximas temperaturas alcançadas nos elementos de concreto número 1 (revestido com argamassa cimentícia), número 2 (revestido com gesso projetado) e número 4 (revestido com gesso formulado) foram, respectivamente, de $198{ }^{\circ} \mathrm{C}$ (ponto 3 ), $283^{\circ} \mathrm{C}$ e $206{ }^{\circ} \mathrm{C}$, correspondentes às medidas dos termopares localizados no ponto 1. Por sua vez, as temperaturas médias nos termopares posicionados nas armaduras (pontos 1, 3 e 5) foram: $543{ }^{\circ} \mathrm{C}$ no elemento sem revestimento, $195{ }^{\circ} \mathrm{C}$ no elemento com argamassa cimentícia, $231^{\circ} \mathrm{C}$ no elemento com gesso projetado e $186^{\circ} \mathrm{C}$ no elemento com gesso formulado liso. Após $24 \mathrm{~h}$ do término de ensaio, o forno foi aberto para inspeção visual dos elementos. Foram observados desplacamentos/lascamentos superficiais distribuídos uniformemente na face exposta ao fogo do elemento de referência, porém sem exposição das armaduras. Nos outros elementos foi verificada a queda parcial dos revestimentos porém nenhum dano superficial no concreto das faces expostas ao fogo, conforme ilustra a Fig. 4.

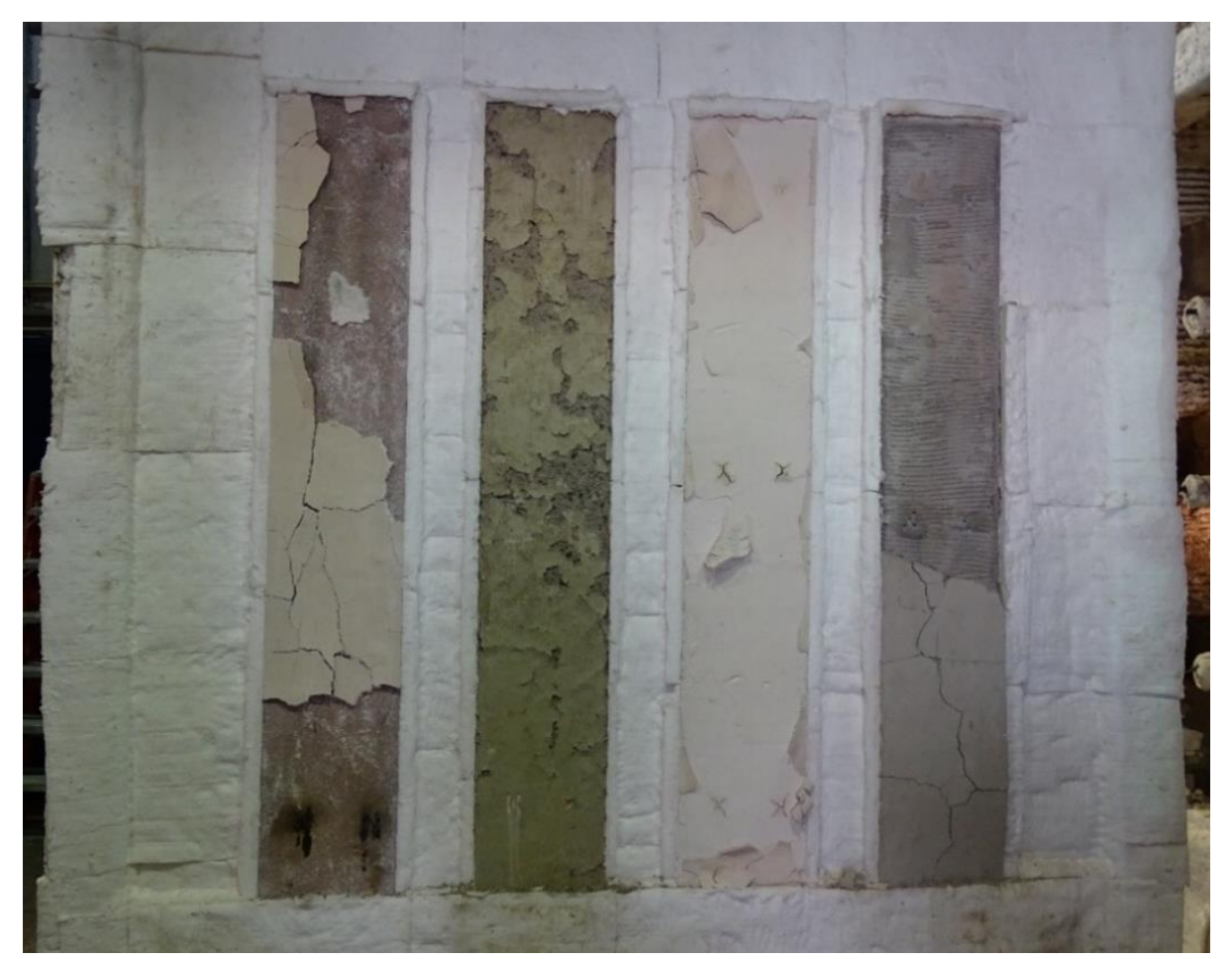

Figura 4. Detalhe da condição dos elementos e revestimentos, após abertura do forno (evento 1).

A amostra de gesso formulado liso ainda possuía um revestimento remanescente quando da abertura do forno (sem quaisquer integridade e aderência), equivalente a $46 \%$ da área total do elemento com face exposta ao fogo. Para a amostra de argamassa cimentícia, esse número foi de $41 \%$. Apurando-se cuidadosamente os elementos, com uso de um martelo de percussão, percebeu-se que os revestimentos remanescentes de gesso formulado liso manual e de argamassa estavam completamente friáveis e a parte ainda remanescente se desplacou quase que espontaneamente, entretanto, os chapiscos aplicados como ponte de aderência estavam íntegros e intactos.

Notadamente, a amostra revestida com o gesso projetado estava ainda com parte do gesso aderida (em $100 \%$ da amostra), parcialmente íntegra e com pouco som cavo. Entretanto, não havia integridade suficiente para um ensaio de arrancamento pelos métodos convencionais, pois a amostra poderia ser 
removida facilmente por raspagem mecânica. Em outras palavras, a camada remanescente estava funcionando somente como uma camada de sacrifício (barreira física) e com pouca aderência. Com uso de um paquímetro digital aferiu-se que houve uma delaminação do gesso projetado com espessura da ordem de $5 \mathrm{~mm}$ e permaneceu remanescente na amostra de concreto uma espessura da ordem de $6 \mathrm{~mm}$ (desvio de $1 \mathrm{~mm}$ do revestimento original previsto de $10 \mathrm{~mm}$ ). Por sua vez, a amostra de referência também chamou atenção pela pouca quantidade e profundidade de spalling. O desplacamento correspondeu a uma área da ordem de $19 \%$ da amostra original numa profundidade típica (máxima) de cerca de $6 \mathrm{~mm}$ (aferida em diversos pontos). Em outras palavras, mesmo no elemento de referência sem revestimento, não houve exposição da armadura que teve cobrimento de $15 \mathrm{~mm}$. Na verdade, não houve exposição da armadura em nenhum elemento ensaiado nesse primeiro evento.

A evolução de temperaturas obtidas no interior das amostras confirmou as análises visuais e qualitativas do desempenho dos revestimentos contrafogo. Conforme observado na Fig. 5, a distribuição de calor foi uniforme no interior da amostra, de acordo com a profundidade de cada termopar. Também se nota que os três termopares da amostra de referência na região do cobrimento se diferenciam muito do restante.

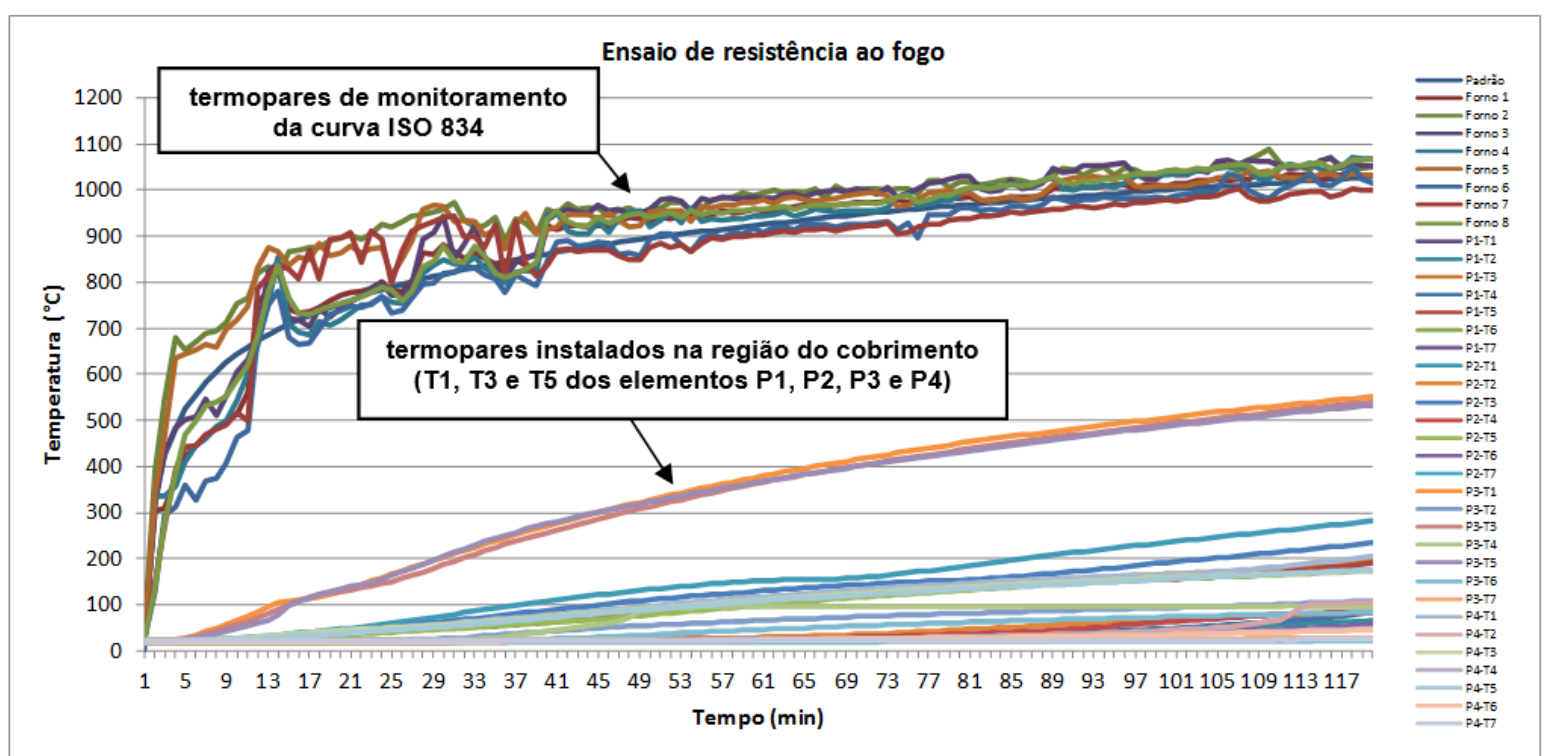

Figura 5. Temperaturas obtidas no interior do forno e no interior dos elementos do evento 1.

\subsection{Segundo evento de ensaio (evento 2)}

$\mathrm{Na}$ data de 05 de setembro de 2018 ocorreu o segundo evento de simulação de incêndio, sob a curva ISO 834 por um tempo de 120 minutos. Aos 53 minutos de ensaio já se observou o desplacamento de todo o revestimento de gesso de mercado desse elemento, bem diferente do ocorrido no primeiro evento de ensaio, levando parte do concreto aderido. Ainda, aos 6 minutos de ensaio, verificou-se o início da atuação da tinta intumescente. Nesse período também se percebeu o início de pequenos lascamentos/desplacamentos superficiais do elemento de referência, sem revestimento. Aos 20 minutos a tinta intumescente apresentava um aspecto de "elementos em brasa" com coloração mais escura e pequenos pontos incandescentes, conforme Fig. 6. 

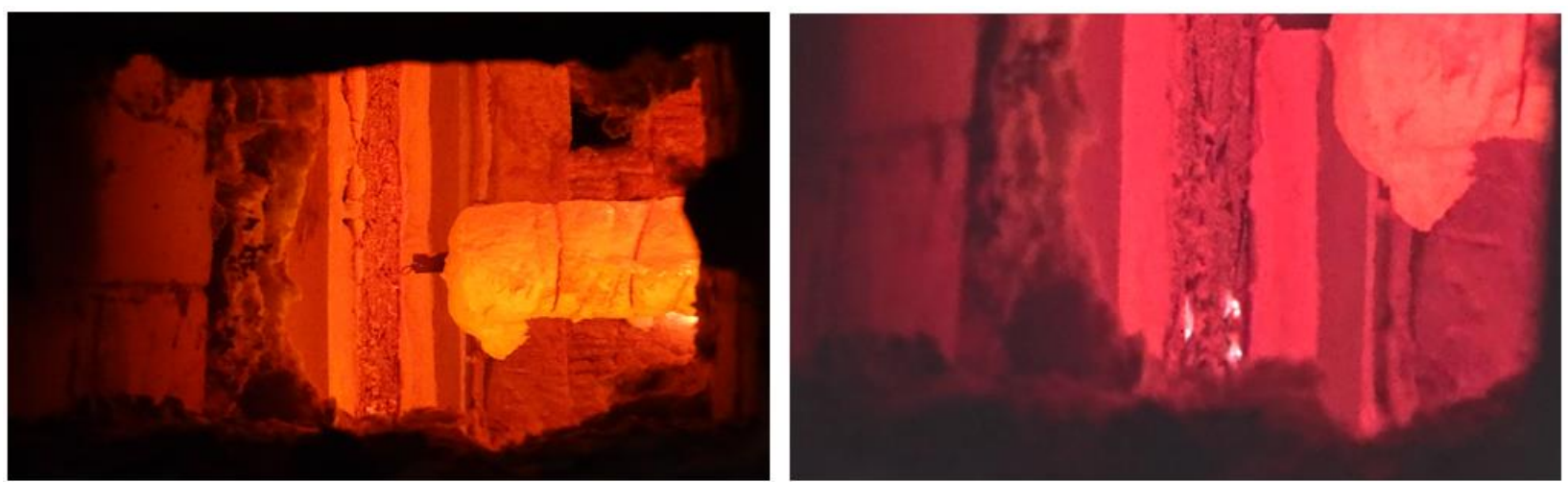

Figura 6 - Detalhe da aparência de "elementos em brasa" do elemento revestido com tinta intumescente (coloração escura à esquerda) e pequenos pontos incandescentes neste mesmo elemento (à direita).

A máxima temperatura atingida no elemento de referência (corpo de prova 3), aos 120 minutos de ensaio, foi de $557^{\circ} \mathrm{C}$, correspondente ao termopar de número 3 localizado na armadura próxima a face exposta ao fogo. Já as máximas temperaturas alcançadas nos elementos de concreto número 1 (revestido com argamassa cimentícia), número 2 (revestido com tinta intumescente) e número 4 (revestido com gesso liso lento popular de mercado) foram de, respectivamente, $255^{\circ} \mathrm{C}$, correspondente à medida do termopar localizado no ponto $3,386^{\circ} \mathrm{C}$, correspondente à medida do termopar localizado no ponto $5 \mathrm{e}$ $559{ }^{\circ} \mathrm{C}$, correspondente à medida do termopar localizado no ponto 1 . Por sua vez, as temperaturas médias nos termopares posicionados nas armaduras (pontos 1, 3 e 5) foram: $533{ }^{\circ} \mathrm{C}$ no elemento sem revestimento, $241^{\circ} \mathrm{C}$ no elemento com argamassa cimentícia, $359{ }^{\circ} \mathrm{C}$ no elemento com tinta intumescente e $487^{\circ} \mathrm{C}$ no elemento com gesso liso lento popular de mercado.

Após $24 \mathrm{~h}$ do término de ensaio, o forno foi aberto para inspeção visual dos elementos. Foram observados lascamentos superficiais distribuídos uniformemente na face exposta ao fogo do elemento de referência, porém sem exposição das armaduras. No elemento revestido com gesso liso lento popular de mercado, observou-se um spalling/desplacamento de grandes proporções na parte superior e nenhum vestígio da ponte de aderência em chapisco (além de 100\% do desplacamento do revestimento de gesso propriamente dito). No elemento revestido com argamassa cimentícia, percebeu-se a presença de todo o chapisco desempenado na base e desplacamento de praticamente todo o revestimento propriamente dito. Finalmente, no elemento revestido com tinta intumescente, detectou-se a presença da mesma (expandida em cor branca, inicial) sem nenhum vestígio aparente da superfície do concreto do elemento ou exposição da armadura, conforme Fig. 7.

Apurando-se cuidadosamente os elementos, com uso de um martelo de percussão, percebeu-se que na amostra revestida com gesso liso de mercado, além do desplacamento de grandes proporções, com exposição da armadura, havia uma camada friável sem nenhuma resistência em praticamente toda a área exposta ao fogo do elemento (na superfície de concreto). $\mathrm{Na}$ amostra de referência, o material perceptível de superfície remanescente também estava friável em toda a área da amostra (região do cobrimento). Não obstante, o chapisco aplicado como ponte de aderência do elemento revestido com argamassa e a superfície de concreto do elemento revestido com tinta intumescente estavam íntegros e intactos.

Resumindo, o concreto estava totalmente íntegro e preservado no caso do revestimento com argamassa cimentícia e com tinta intumescente, não apresentando quaisquer sinais de um material tipicamente friável ou de armadura exposta. Com uso de uma trena, aferiu-se uma área de desplacamento (spalling) na amostra revestida com gesso liso lento de mercado, onde ocorreu a exposição da armadura, sendo a mesma de aproximadamente $20 \%$ da área total, lembrando que a área remanescente estava friável em toda a superfície, muito semelhante com a amostra de referência, até em questões de profundidade de 
dano, sugerindo que o revestimento em gesso de mercado se desplacou bem antes do observado no evento 1 .

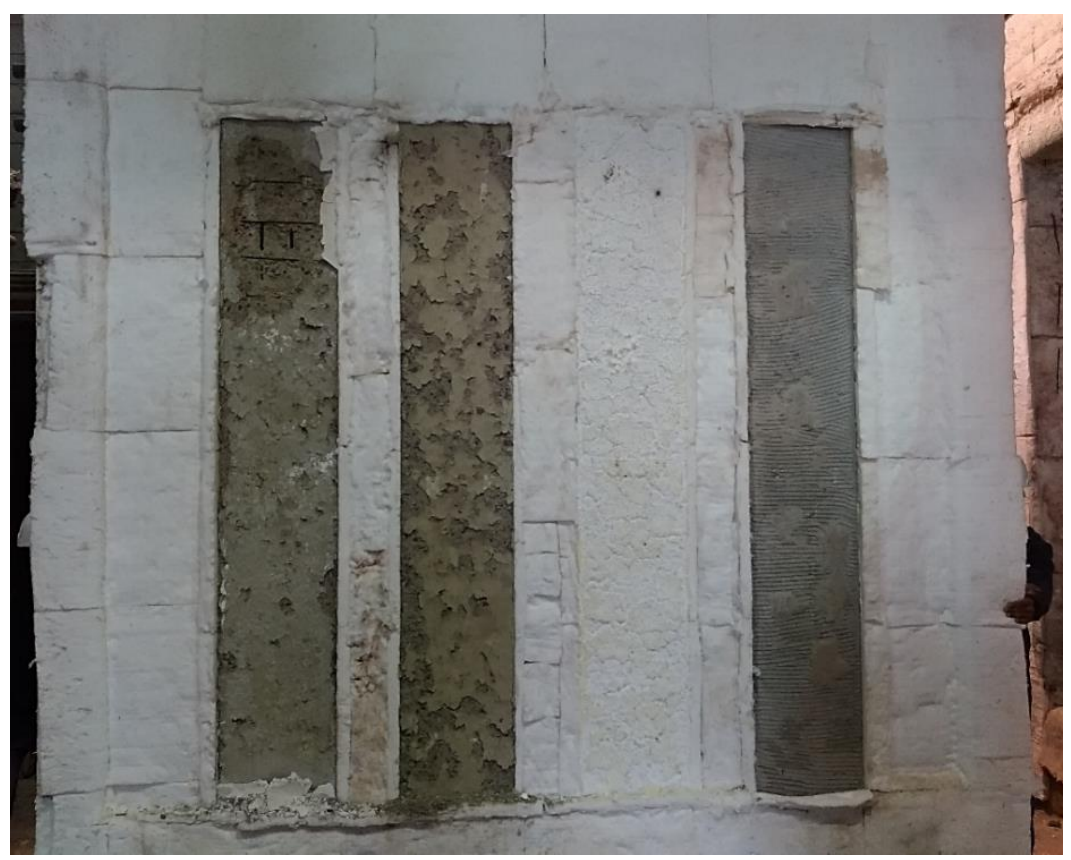

Figura 7. Detalhe da condição dos elementos e revestimentos, após abertura do forno (evento 2).

Ainda, de toda a armadura equivalente daquela face exposta ao fogo, passível de exposição, foi aferido que somente $6 \%$ foi de fato exposta. Notadamente, a amostra revestida com tinta intumescente protegeu bem o elemento de concreto, sem nenhum indicativo de lascamento ou desplacamento. A superfície estava tão íntegra e bem-acabada que, caso fosse bem limpa, dificilmente poder-se-ia afirmar que a mesma fora submetida a um ensaio de simulação de incêndio.

Com o uso de um paquímetro digital, aferiu-se que houve um desplacamento severo na amostra revestida com gesso liso lento popular de mercado, da ordem de $19 \mathrm{~mm}$ a $27 \mathrm{~mm}$ (máximo) numa área de aproximadamente $20 \%$ da área total da amostra (cerca de $60 \mathrm{~cm} \times 30 \mathrm{~cm}$ ), como ilustra a Fig. 7. Por sua vez, a parte friável remanescente possuía uma espessura da ordem de $2 \mathrm{~mm}$ a $3 \mathrm{~mm}$ (Fig. 7), inferior à das amostras de referência de ambos os eventos, como será observado adiante.

Por sua vez, a amostra de referência também chamou atenção pela pouca quantidade e profundidade de spalling. O desplacamento correspondeu a uma área da ordem de $40 \%$ da amostra original numa profundidade típica (máxima) de cerca de 7,5 mm (aferida em diversos pontos), somente, embora a amostra estivesse com $100 \%$ da área de exposição ao fogo friável nessa mesma profundidade aferida. Em outras palavras não houve exposição da armadura (com cobrimento mínimo de $15 \mathrm{~mm}$ ). Na verdade, somente houve exposição da armadura no elemento com gesso liso lento popular de mercado no segundo evento de ensaio (em particular com desempenho inferior à amostra de referência, sem revestimento). Também foi aferida a expansão da tinta intumescente remanescente na amostra ao longo de toda a sua área exposta ao fogo. Nesse caso, a mesma não possuía nenhuma aderência, sendo removida facilmente com uma espátula (manualmente). A partir da área raspada, foi possível aferir com um paquímetro uma expansibilidade de $110 \mathrm{~mm}$ a $112 \mathrm{~mm}$, o que corresponde da ordem de 30 vezes a espessura aplicada originalmente de 390 micrometros seca (DFT), condizente com as especificações do fabricante.

A evolução de temperaturas obtidas no interior das amostras também confirmou as análises visuais e qualitativas do desempenho dos revestimentos contrafogo. Conforme observado na Fig. 8, a distribuição de calor foi uniforme no interior da amostra de acordo com a profundidade de cada 
termopar. Também se nota uma elevação substancial da temperatura nos três termopares da amostra de referência na região do cobrimento, bem como nos três referentes à amostra revestida com gesso liso lento popular de mercado, a partir dos 53 min (realçado em vermelho), onde provavelmente houve o desplacamento total do revestimento levando consigo parte do concreto aderido e expondo a armadura. Esse comportamento se diferencia muito do apresentado pelo restante dos termopares.

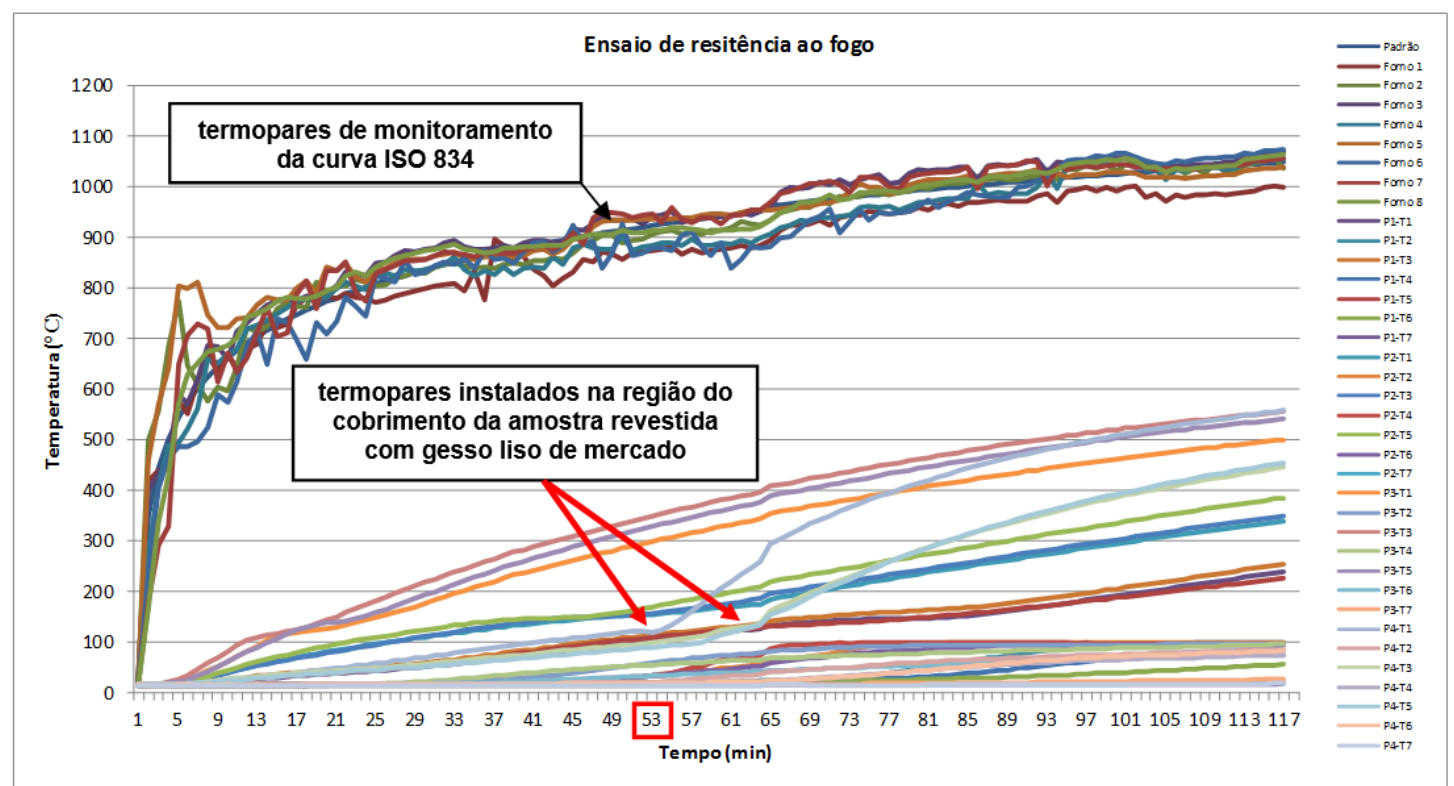

Figura 8. Temperaturas obtidas no interior do forno e no interior dos elementos do evento 2.

\section{DISCUSSÃO DOS RESULTADOS E ENSAIOS COMPLEMENTARES}

Em geral, pode-se afirmar que se obteve em todos os elementos, exceto na amostra com gesso liso lento popular de mercado (a qual será analisada separadamente por meio de exames complementares), um bom desempenho quando expostos ao fogo por 120min ( $2 \mathrm{~h}$ ), com o concreto mantendo praticamente sua integridade original nos elementos revestidos e com danos inferiores a 7,5 $\mathrm{mm}$ de profundidade de desplacamento nas amostras de referência, para um cobrimento de somente $15 \mathrm{~mm}$ (não expondo a armadura). Nessas amostras de referência, apesar de um desplacamento inicial aferido entre $19 \%$ e $40 \%$ da área total, para as amostras do primeiro e segundo evento respectivamente, após inspeção por meio de martelo de percussão, pode-se afirmar seguramente que $100 \%$ da área de exposição ao fogo estava completamente friável nessa mesma profundidade, ou seja, em termos integridade, poder-se ia considerar da ordem $6 \mathrm{~mm}$ de profundidade de dano na amostra de referência do primeiro evento e da ordem de 7,5 mm do segundo evento, valores esses considerados irrelevantes frente às $2 \mathrm{~h}$ de ensaio, sob a curva ISO 834.

Ainda, sobre as temperaturas aferidas (nas amostras de referência), tem-se muita similaridade entre os dois eventos de ensaio, como se pode observar nas Fig. 5 e 8 (no máximo $10^{\circ} \mathrm{C}$ de diferença). Nesse caso, na média dos dois eventos de ensaio, pode se afirmar que $15 \mathrm{~mm}$ de espessura de cobrimento de concreto (sem quaisquer revestimentos) foi suficiente para registrar uma temperatura inferior a $550{ }^{\circ} \mathrm{C}$ $\left(\right.$ em média $538^{\circ} \mathrm{C}$ ), para uma temperatura de praticamente $1000^{\circ} \mathrm{C}$ dentro do forno em 120 minutos de ensaio. Ou seja, o cobrimento de $15 \mathrm{~mm}$ "barrou" uma temperatura da ordem de $450{ }^{\circ} \mathrm{C}$, sem qualquer exposição de armadura para um desplacamento máximo de $7,5 \mathrm{~mm}$ com o restante do cobrimento (da ordem de 50\%) ainda bastante íntegro, conforme exposto na Tabela 1. 
Tabela 1. Comparativo de eficiência de cada tipo de revestimento em "barrar" a temperatura média nos termopares 1, 3 e 5, posicionados na armadura (região do cobrimento), aos 120 min de ensaio (com relação ao elemento de referência).

\begin{tabular}{|c|c|c|c|c|}
\hline $\begin{array}{l}\text { Evento de } \\
\text { ensaio }\end{array}$ & Amostras em comparação & $\begin{array}{l}\text { Temperatura } \\
\left.\text { média ( }{ }^{\circ} \mathrm{C}\right)\end{array}$ & Diferença & Isolamento \\
\hline \multirow{6}{*}{ Evento 1} & Referência (sem revestimento) & 543 & \multirow{2}{*}{348} & \multirow{2}{*}{$64 \%$} \\
\hline & Revestida com argamassa industrializada base cimento $(25 \mathrm{~mm})$ & 195 & & \\
\hline & Referência (sem revestimento) & 543 & \multirow{2}{*}{357} & \multirow{2}{*}{$66 \%$} \\
\hline & Revestida com gesso formulado liso (10mm) & 186 & & \\
\hline & Referência (sem revestimento) & 543 & \multirow{2}{*}{312} & \multirow{2}{*}{$57 \%$} \\
\hline & Revestida com gesso projetado (10mm) & 231 & & \\
\hline \multirow{6}{*}{ Evento 2} & Referência(sem revestimento) & 533 & \multirow{2}{*}{292} & \multirow{2}{*}{$55 \%$} \\
\hline & Revestida com argamassa industrializada base cimento $(25 \mathrm{~mm})$ & 241 & & \\
\hline & Referência (sem revestimento) & 533 & \multirow[b]{2}{*}{174} & \multirow[b]{2}{*}{$33 \%$} \\
\hline & $\begin{array}{l}\text { Revestida com tinta intumescente ( } 540 \text { micrometros WFT / } 390 \\
\text { micrometros DFT) }\end{array}$ & 359 & & \\
\hline & Referência(sem revestimento) & 533 & \multirow{2}{*}{46} & \multirow{2}{*}{$9 \%$} \\
\hline & Revestida com gesso liso lento popular de mercado ( $10 \mathrm{~mm})$ & 487 & & \\
\hline
\end{tabular}

Especificamente sobre os revestimentos com argamassa, nota-se que, provavelmente, até pelas temperaturas obtidas, os mesmos se desprenderam do chapisco de base, bem no final ou até mesmo após o término do ensaio, durante o resfriamento natural (o forno foi aberto $24 \mathrm{~h}$ após o término do ensaio). Fato interessante é que o chapisco desempenado aplicado diretamente sobre o elemento de concreto (com desempenadeira dentada de $8 \mathrm{~mm} \times 8 \mathrm{~mm}$ ) estava completamente aderido e intacto, proporcionando um concreto absolutamente íntegro nas duas amostras revestidas com esse sistema. Nesse contexto, os $2,5 \mathrm{~cm}$ de espessura revestimento de argamassa funcionaram bem como uma camada de sacrifício durante os dois eventos de ensaio. As temperaturas aferidas no interior da amostra corroboram essas considerações. Nos gráficos das Fig. 5 e 8 observa-se uma linearidade na evolução dos valores aferidos de temperatura, o que condiz com uma transmissão de calor sem interferência, ou seja, sem desplacamentos durante o evento de ensaio (considerando até os revestimentos nesse caso). Um comportamento anômalo, por exemplo, um pico ou uma taxa de crescimento descontínua da temperatura, poderia indicar um desplacamento localizado ou até a exposição da armadura (que aumentaria sobremaneira os valores de temperatura aferidos, com uma taxa bem mais rápida de aquecimento comparada à do concreto, pela diferença significativa da condutividade térmica desses dois materiais).

No caso da tinta intumescente, pôde-se perceber que a mesma, rapidamente entrou na intumescência propriamente dita nos primeiros minutos do evento de ensaio, fato esperado em função da ação desse tipo de reação química expansiva se iniciar aproximadamente em $200{ }^{\circ} \mathrm{C}$ (a curva ISO 834 alcança da ordem de $550^{\circ} \mathrm{C}$ nos primeiros cinco minutos). O mais surpreendente nesse caso é que somente a espessura de aplicação de 390 micrometros (três demãos / DFT) foi suficiente para garantir a completa integridade do elemento estrutural, preservando totalmente a superfície original da amostra. Apesar da impressão de "elemento em brasa" e sinais de incandescência, não houve comprometimento em 100\% da área exposta ao fogo, embora com temperaturas internas aferidas superiores as registradas no revestimento com argamassa, por exemplo.

O que chamou atenção e motivou ensaios e exames químicos complementares foram as análises da integridade das amostras revestidas com gesso. No primeiro evento, constatou-se que o gesso formulado liso aplicado com desempenadeira de aço preservou totalmente a integridade do elemento de concreto, inclusive com sinais evidentes e claros da base de chapisco rolado ainda aderida. Nesse caso, presumese que ocorreu o mesmo efeito dos revestimentos com argamassa, ou seja, o mesmo se desprendeu bem 
no final ou até após o término do ensaio, durante o resfriamento natural, proporcionando um concreto absolutamente íntegro na amostra revestida com esse sistema. Nesse contexto, somente 1,0 cm de espessura de revestimento do gesso formulado liso funcionou bem como uma camada de sacrifício.

Por sua vez, nesse mesmo evento, o gesso projetado apresentou uma delaminação da ordem de $50 \%$ de sua espessura, conforme constatações do item precedente. Isso também preservou bastante a integridade da amostra de concreto, que ainda ficou protegida por aproximadamente $6 \mathrm{~mm}$ de gesso. Por outro lado, esse gesso remanescente possuía pouca aderência e estava com som cavo e superfície macia/fofa quando submetida aos ensaios de percussão com martelo de aço. Isso leva a crer, até pelas temperaturas internas, que a delaminação ocorreu de fato durante o ensaio de simulação de incêndio (pelas inspeções realizadas, entre 30 a 40 minutos do início do ensaio). Ou seja, por um período de 80 a 90 minutos de ensaio, esse elemento fora protegido somente por $6 \mathrm{~mm}$ de espessura de gesso projetado. É interessante comparar essas considerações com os valores registrados de temperaturas. Apesar de uma espessura de gesso remanescente após a finalização do ensaio, as temperaturas internas foram um pouco superiores quando comparadas à amostra de gesso formulado liso, o que leva a crer que houve mesmo uma delaminação durante o ensaio e que uma espessura menor funcionou como camada de sacrifício (por um período da ordem de 80 a 90 minutos, no final do ensaio). Registrou-se, aos 120 minutos de ensaio, em média, $231{ }^{\circ} \mathrm{C}$ no elemento revestido em gesso projetado, temperatura aproximadamente $25 \%$ maior quando comparado ao gesso formulado liso ( $186^{\circ} \mathrm{C}$ aos 120 minutos). Lembra-se que são materiais de mesma natureza, inclusive com composição química, mineralógica e térmica bem similares, o que corrobora a delaminação mais precoce no gesso projetado (talvez em função do método de aplicação) e a preservação do gesso formulado liso durante todo o primeiro evento de ensaio (desprendimento somente após o resfriamento do forno).

Especificamente sobre o revestimento em gesso liso lento popular de mercado, aplicado no segundo evento de ensaio, com os mesmos procedimentos do gesso formulado liso do primeiro evento, nota-se que houve uma significativa diferença nos resultados obtidos, representada por um desplacamento expressivo (spalling severo) do concreto, inclusive com exposição de armadura. Observa-se que essa foi a única amostra onde houve exposição da armadura, das oito ensaiadas nos dois eventos distintos de ensaio. Destaca-se que não houve spalling nas amostras sem revestimento (de referência). $O$ desplacamento observado foi de uma área aproximada de $60 \mathrm{~cm} x 30 \mathrm{~cm}$, com profundidade máxima de $27 \mathrm{~mm}$, o que já foi suficiente para expor a armadura, com cobrimento de $15 \mathrm{~mm}$. Não obstante, da área total de armadura passível de exposição, somente $6 \%$ foi realmente exposta.

Com base nas temperaturas monitoradas, acredita-se que o desplacamento de maior proporção ocorreu entre 40 e 50 minutos do evento, uma vez que o comportamento da evolução das temperaturas internas dos termopares situados na região do cobrimento se alterou de forma drástica a partir de aproximadamente 55 minutos. O comportamento até os 55 minutos estava bastante similar com as amostras de gesso do primeiro evento de ensaio. A partir desse instante, houve uma mudança repentina na taxa de aquecimento interna, registrada principalmente pelo termopar 1 e posteriormente nos outros termopares, o que leva crer que já havia ocorrido o desplacamento, com exposição de armadura e uma mudança nos registros, em função da condutividade térmica do aço (a primeira linha de termopares estava fixada na armadura longitudinal limítrofe do cobrimento). A temperatura média aferida nos três termopares foi de $487^{\circ} \mathrm{C}$, com máxima de $559^{\circ} \mathrm{C}$, ou seja, praticamente a mesma temperatura das amostras de referência, que apresentaram picos de $553{ }^{\circ} \mathrm{C}$ e $557{ }^{\circ} \mathrm{C}$ nos dois eventos de ensaio, respectivamente.

Como todo o estudo experimental foi planejado para haver a menor quantidade de variáveis possíveis [elementos construídos na mesma oportunidade, com o mesmo concreto, procedimentos e mão de obra; mesmo profissional aplicando os revestimentos de gesso desempenado (formulado liso e liso lento popular de mercado, independentemente da procedência) nos elementos, ensaios de simulação de incêndio em mesmas condições etc.)], presumiu-se que o agente causador do comportamento anômalo poderia estar de fato relacionado exclusivamente com o material aplicado (gesso liso lento popular de 
mercado). Isso posto, decidiu-se pela elaboração e realização de um plano de ensaios e exames químicos e térmicos complementares nas três amostras envolvidas no estudo experimental: gesso formulado liso M30 e gesso projetado P80 e gesso liso lento popular de mercado.

Amostras do mesmo lote dos gessos empregados no estudo experimental foram coletadas e separadas, a fim de se identificar qualquer alteração, impureza ou material estranho. Resultados da análise química semiquantitativa por fluorescência de raios-X já indicaram uma diferença significativa em "Perda ao Fogo" e "Anidrido Sulfúrico". Na amostra do gesso liso popular de mercado, o valor obtido de perda ao fogo diferiu $120 \%$ e o anidrido sulfúrico da ordem de $35 \%$ com relação às amostras de gesso formulado e projetado do primeiro evento de ensaio que, por sua vez, foram bastante similares. No caso do anidrido sulfúrico, nota-se que o valor obtido no ensaio estava ainda $25 \%$ abaixo do limite requerido na norma ABNT NBR 13207:2017 - Gesso para construção civil - Requisitos, ou seja, a amostra comercializada não segue os limites normativos prescritos. Concomitantemente foram realizadas análises termogravimétricas (TG/DTG) (análise térmica diferencial e termogravimétrica simultânea) para identificar as perdas de massa, onde os valores de perda ao fogo foram confirmados com diferenças mínimas das obtidas nas análises químicas semiquantitativas por fluorescência de raios-X. A perda ao fogo elevada na amostra de gesso liso lento popular de mercado, confirmada por dois métodos de ensaios [análises químicas semiquantitativas por fluorescência de raios-X e análises termogravimétricas (TG/DTG) (análise térmica diferencial e termogravimétrica simultânea)], pode estar associada ao volume elevado de $\mathrm{CO}_{2}$ liberado pela decomposição térmica dos carbonatos presentes (dolomita e calcita), conforme será constatado adiante. Ainda, a fim de se identificar alguma diferença que pudesse justificar a diferença no comportamento ao fogo do revestimento com gesso liso lento popular de mercado, foram procedidas análises mineralógicas quantitativas por difração raios-X. Em suma, pôdese observar uma grande diferença na amostra de gesso liso lento popular de mercado quando comparada com as de gesso formulado liso e gesso projetado, principalmente nos teores de bassanita e dolomita. Assim, acredita-se que, certamente, a presença de um maior teor de carbonatos (dolomita e calcita), identificada na decomposição térmica da amostra de gesso liso lento popular de mercado em proporções elevadas (quando comparada às amostras de gesso formulado liso e gesso projetado), vai gerar um significativo volume de anidrido carbônico que, combinado com um ambiente de rápida taxa de aquecimento e excessivas temperaturas no interior do forno (caracterizados pela curva ISO 834), vai gerar, consequentemente, pressão de expansão em maior escala, resultando o desplacamento expressivo constatado (spalling severo), inclusive com exposição de armadura (justificando o quadro constatado no ensaio do evento 2). Em outras palavras, acredita-se simplesmente que, se a amostra de gesso liso lento de mercado cumprisse com as prescrições mínimas da normalização vigente (livre ainda de elevados teores de materiais carbonáticos), assim como as amostras do gesso formulado liso e gesso projetado, o comportamento ao fogo dos revestimentos em gesso seria bem parecido.

\section{CONCLUSÕES}

Quanto aos resultados obtidos nos dois eventos de ensaio de simulação de incêndio, pôde notar claramente, no evento 1 (amostras de gesso formulado liso e gesso projetado, a eficiência de $250 \%$ do revestimento de gesso em relação à amostra revestida com argamassa industrializada, inclusive parametrizado com a amostra de referência. A diferença dos termopares instalados na região do cobrimento [valores médios de $195^{\circ} \mathrm{C}$ (argamassa) e $186^{\circ} \mathrm{C}$ (gesso)] é de somente $9{ }^{\circ} \mathrm{C}$ (inferior a 5\%), lembrando que o revestimento de gesso liso possui $1 \mathrm{~cm}$ e o de argamassa $2,5 \mathrm{~cm}$ (proporção de $1: 2,5$ ). Raciocinando de forma expedita, admitindo uma taxa linear de crescimento de temperatura no interior das amostras, tem-se que o revestimento de argamassa base cimento equivale também a $100 \%$ do cobrimento de concreto, em termos de eficiência, conforme informado em literatura (SILVA, 2012). Fato é que a espessura conjugada de revestimento de argamassa com o cobrimento de concreto importa em $40 \mathrm{~mm}$ até a região do primeiro termopar $(15 \mathrm{~mm}$ do cobrimento de concreto $+25 \mathrm{~mm}$ do 
revestimento em argamassa); relacionando essa espessura conjugada de $40 \mathrm{~mm}$ com o cobrimento de $15 \mathrm{~mm}$ (do elemento de referência, sem revestimento) tem-se o coeficiente de 2,7, o que corresponde a praticamente ao mesmo coeficiente (de 2,8) da relação entre as temperaturas aferidas nesses pontos $\left(543{ }^{\circ} \mathrm{C}\right.$ aferido no elemento de referência e $195^{\circ} \mathrm{C}$ aferido no elemento revestido com argamassa industrializada base cimento).

Ainda, considerando que a tinta intumescente barrou aproximadamente $50 \%\left(174{ }^{\circ} \mathrm{C}\right)$ da temperatura [quando comparada às amostras de gesso e argamassa do evento 1 , de $348^{\circ} \mathrm{C}$ para o revestimento de gesso formulado liso e $357^{\circ} \mathrm{C}$ para o revestimento de argamassa], poder-se-ia presumir que a mesma, nesse evento de ensaio, deveria possuir o dobro de sua espessura aplicada, ou aproximadamente 1000 micrometros $(1 \mathrm{~mm})$ WFT para barrar uma temperatura de mesma ordem. Não obstante, em questões de eficiência dos três revestimentos (argamassa, gesso e tinta intumescente), considerando o gesso formulado liso equivalente ao gesso projetado e excluindo o comportamento do gesso liso lento popular de mercado, tem-se, por extrapolação, sobre as taxas de eficiência, no que tange ao desempenho de revestimento contrafogo em elementos de concreto armado, que uma espessura de argamassa equivaleria à mesma espessura do concreto de referência $(100 \%, 1: 1)$, essa espessura dividida por 2,5 equivaleria à espessura de gesso $(250 \%$ de eficiência, 2,5:1) e, ainda, essa espessura dividida por 25 equivaleria à espessura de tinta intumescente $(2500 \%, 25: 1)$. Evidentemente, que não foi comprovado nessa pesquisa a correlação da espessura e, consequentemente, eficiência da tinta intumescente em $2500 \%$ (em relação ao revestimento de argamassa e ao concreto de referência), entretanto, a mesma foi extrapolada em função das temperaturas obtidas nos eventos de ensaio de simulação de incêndio.

Em outro aspecto, destaca-se a importância da caracterização das propriedades do gesso que, ao que parece, possui comportamento singular e que interfere bastante no desempenho do revestimento quando usado como alternativa contrafogo. Em face ao exposto nessa pesquisa, é indispensável que o gesso usado para essa finalidade (revestimento contrafogo) cumpra com os requisitos básicos prescritos em norma e não contenha impurezas com elevados teores de materiais carbonáticos, que podem acarretar em desplacamentos severos em ambientes de elevadas temperaturas, inclusive com spalling do elemento de concreto, em virtude da geração de elevados volumes de anidrido carbônico e, consequentemente, pressões expansivas em maior escala.

\section{REFERÊNCIAS BIBLIOGRÁFICAS}

Alexander, B. (1982), Behaviour of gypsum and gypsum products at high temperatures. RILEM Committee PHT-44, British Gypsum, East Leake, Loughborough, England March.

Almeida, D. F. (1984), As estruturas de concreto armado e o fogo, comportamento, consequências, restauração. Dissertação (mestrado) - Escola Politécnica, Universidade de São Paulo, São Paulo.

Associação Brasileira de Normas Técnicas (2014). NBR 6118: Projeto de estruturas de concreto, procedimentos. Rio de Janeiro, 2014. 238 p.

Associação Brasileira de Normas Técnicas (2017). NBR 13207: Gesso para construção civil Requisitos. Rio de Janeiro, 2017. 3 p.

Associação Brasileira de Normas Técnicas (2001). NBR 14432: Exigências de resistência ao fogo de elementos construtivos de edificações, Procedimento. Rio de Janeiro, 2001. 14 p.

Associação Brasileira de Normas Técnicas (2004). NBR 15200: Projeto de estruturas de concreto em situação de incêndio (cancelada). Rio de Janeiro, 2004. 17 p.

Associação Brasileira de Normas Técnicas (2012). NBR 15200: Projeto de estruturas de concreto em situação de incêndio. Rio de Janeiro, 2012. 48 p.

Atefi, H.; Nadjai, A.; Ali, F. (2017), Numerical and experimental investigation of the thermal behaviour of coated cellular beamns with intumescent coatings at elevated temperatures. In: IFireSS $2017-2^{\text {nd }}$ International Fire Safety Symposium. Naples, Italy, June 7-9. p. 257-264. 
Kodur, V.K.R. (2005), Guidelines for fire resistance design of high-strength concrete columns. Ottawa, Ontário, Canadá: IRC/NRC. (Report NRCC-47729). Disponível em: <http://irc.nrccnrc.gc.ca/pubs/fulltext/nrcc47729/>. Acesso em: novembro de 2007.

Landi, F. R. (1986), Ação do incêndio sobre as estruturas de concreto armado. Boletim técnico $\mathrm{n}^{\circ}$ 01/86. São Paulo: Escola Politécnica, Universidade de São Paulo. 24p.

Lucherini, A.; Maluk, C. (2017), Novel test methods for studying the fire performance of thin intumescent coatings. In: IFireSS $2017-2^{\text {nd }}$ International Fire Safety Symposium. Naples, Italy, June 7-9. p. 565-572.

Malhotra, H. L. (1982), Properties of Materials at High Temperatures - Report on the work of technical committee 44-PHT. Materials and Structures/Matériaux et Constructions. Vol. 15. $\mathrm{N}^{\circ} 86$. RILEM, Paris.

Ogrin, A.; Saje, M.; Hozjan, T. (2017), Effect of incomplete expansion of intumescent coating on mechanical response of steel frame in fire. In: IFireSS $2017-2^{\text {nd }}$ International Fire Safety Symposium. Naples, Italy, June 7-9. p. 365-372.

Silva, D.; Bilotta, A.; Nigro, E. (2017), Experimental analysis on the effectiveness of intumescent coatings in fire. In: IFireSS $2017-2^{\text {nd }}$ International Fire Safety Symposium. Naples, Italy, June 7-9. p. 249-256.

Silva, V. P. (2007), Considerações sobre as normas brasileiras de estruturas em situação de incêndio. 7 p. Artigo científico. Revista Incêndio, $\mathrm{n}^{\circ} 46$. 